\title{
A TEORIA CRÍtica DE HABERMAS FRENTE À PERSPECTIVA ONTO-PRÁTICA DE MARX
}

\author{
ZAIRA RODRIGUES VIEIRA ${ }^{1}$
}

O presente texto busca suscitar os pontos centrais de divergência do Habermas de fins da década de 60 até metade da década de 70 com Marx no que diz respeito às estruturas de dominação social e à emancipação humana objetivada por cada um deles. A teoria social de Habermas volta-se, já neste período, de forma decisiva para o campo da 'prática' - entendido como sendo o campo da formação da vontade e das tomadas de decisões pela interação comunicativa.

Habermas parte da rejeição da teoria do valor-trabalho de Marx e o faz com a justificativa de que

“...a tecnologia e a ciência se transformam na principal força produtiva, tornando inoperantes as condições da teoria do valortrabalho de Marx. Já não faz sentido calcular a quantidade de investimento de capital na pesquisa e no desenvolvimento tendo como base o valor da força de trabalho não-especializada (simples), quando o progresso científico-técnico se torna uma fonte independente de mais-valia, em relação ao qual a única fonte de mais-valia considerada por Marx, isto é, a força de trabalho dos produtores imediatos, desempenha um papel cada vez menor ${ }^{2}$.

\footnotetext{
${ }^{1}$ Mestranda do Departamento de Filosofia da Universidade Federal de Minas Gerais (UFMG).

${ }^{2}$ Apud I. Meszáros, O Poder da Ideologia. São Paulo: Ensaio, 1986, p.180.
} 
Ao rejeitar, desta forma, a teoria do valor-trabalho, Habermas comete, primeiro, uma distorção do pensamento de Marx e, depois, uma unilateralização de perspectiva que marcará todo o resto de sua obra.

O que são, segundo Marx, a ciência e a técnica senão formas objetivadas da força de trabalho humana apropriadas pelo capital? Habermas dilui a contradição capital/trabalho numa realidade não problemática do desenvolvimento do "capitalismo avançado, organizado" ao desvincular a ciência e a técnica da força de trabalho humana. Vejamos, porém, o que diz Marx:

"O desenvolvimento dos meios de trabalho, que leva à produção de máquinas, não é um momento acidental do capital, mas o remodelamento histórico dos meios de trabalho tradicionais em uma forma adequada ao capital. A acumulação de conhecimento e de habilidade das 'forças produtivas gerais do cérebro social' é assim absorvida pelo capital enquanto oposto ao trabalho (...). Além disso, na medida em que a maquinaria se desenvolve com a acumulação da ciência da sociedade, da força produtiva em geral, o trabalho social geral já não se apresenta no trabalho, mas no capital. A força produtiva da sociedade é medida pelo capital fixo $(\ldots)^{3}$.

Ou seja, ciência e tecnologia não são outra coisa que não as formas que tomaram as forças produtivas sociais; a "ciência da sociedade" não é senão "força produtiva em geral", isto é, as forças produtivas sociais objetivadas e apropriadas pelo capital.

De um lado, Marx não reconhece, como Habermas o pretende, apenas a força de trabalho simples, mas a transformação "do processo de trabalho simples em um processo científico [o qual] ... surge como uma qualidade do capital fixo, em contraposição ao trabalho vivo"“. De outro lado, Marx também não reconhece uma ciência e tecnologia "independentes" do trabalho vivo. Como bem o expressa Mészáros, para aquele autor, "O trabalho vivo, juntamente com a ciência e a tecnologia, constitui uma unidade com-

\footnotetext{
${ }^{3}$ Karl Marx, Manuscrits de 1857-1858 (Grundrisse), tomo I. Paris: Editions Socialrs, 1968, p. 393.

${ }^{4}$ Idem, p. 399.
}

56 A TEORIA CRÍTICA DE HABERMAS FRENTE À PERSPECTIVA ONTO-PRÁTICA DE MARX 
plexa e contraditória sob as condições dos desenvolvimentos capitalistas por mais 'organizados' e 'avançados' que sejam",

A unilateralização em que incorre Habermas decorre exatamente deste seu entendimento quanto às forças produtivas. Embora contraditoriamente as utilize para dizer que a ciência e a tecnologia são, no capitalismo avançado, a principal força produtiva, as categorias marxianas das forças produtivas e relações de produção são substituídas pelo par "trabalho e interação". A dinâmica interna do desenvolvimento produtivo é extraída de seu meio capitalista: ciência e tecnologia adquirem independência quanto às relações sociais de produção. Elas, que, para Habermas, são as forças produtivas atuais, são extraídas do contexto contraditório das relações produtivas para serem situadas sob o domínio do consenso, isto é, da política. No par "mais abstrato" - como o próprio Habermas o denomina - trabalho e interação, esta última é que rege as relações do âmbito do trabalho. O capitalismo é identificado apenas enquanto instituições e não mais como unidade contraditória que tem como fulcro o capital e o trabalho. Podemos, assim, aplicar a Habermas a crítica que Rosa Luxemburgo fez a Berstein pelo fato de que "por capitalista ele não entende uma categoria de produção, mas de direitos de propriedade" . Assim o fazendo, "ele desloca a questão do socialismo do reino da produção para o reino das relações de fortuna (...) da relação entre capital e trabalho para a relação entre ricos e pobres" ${ }^{\text {". Em Ha- }}$ bermas, o transplante redutivo da categoria do capital para a esfera das relações políticas tem a função de diluir a contradição do capitalismo no modus operandi do estado intervencionista.

Para este autor, a esfera da ação prática, entendida como sendo a da política, é a esfera reguladora, e isto não importa em que tipo social. Assim o era nas sociedades primitivas, onde a racionalidade comunicativa era, segundo ele, predominante, mas também continua a sê-lo independente da forma que o capitalismo assuma. A política é a esfera reguladora tanto no chamado capitalismo liberal quanto no estado moderno. Trata-se, na verda-

\footnotetext{
${ }^{5}$ Meszáros, O Poder da Ideologia, op. cit., p. 183.

${ }^{6}$ Apud Meszáros, O Poder da Ideologia, op. cit., p. 181.
} 
de, de uma concepção epistemologizante, onde a subjetividade é ad eternum o elemento preponderante na determinação do todo social. Os problemas que intervêm neste quadro do capitalismo avançado são, segundo Habermas, da ordem da dominação de classe. Classes, estas, determinadas, porém, não no âmbito da produção, mas no da reprodução circular da dominação política, onde o que está em jogo é a volição. Superada a necessidade do trabalho humano, a dominação social é reproduzida por uma lógica interna a ela mesma, a lógica de um discurso deteriorado. Segundo Habermas, não é mais a penúria de ordem física, ou material, mas "a satisfação de ordem masoquista de uma forma de dominação que bloqueia uma atenuação objetivamente possível da luta pela existência e impede uma interação sem coerção sobre a base de uma comunicação livre de dominação"7. A dominação assume a forma de um masoquismo social constituído por falta de vontade política, de um lado, e de consciência da dominação, de outro.

Habermas, ele próprio, explicita o caráter especulativo de suas preocupações quando das questões que se coloca para análise no estado moderno: "As motivações que dão forma à consciência política" ${ }^{8}$. A realidade efetiva das classes tendo sido relegada ao segundo plano - já que não é mais o plano do todo contraditório que é tido em conta, mas apenas partes deste, e que, de outro lado, o econômico não se garante mais por si só no capitalismo avançado - resta apenas a vontade coletiva comum a ser constituída e, portanto, perquirida em suas motivações.

Segundo Marx, é precisamente por se sentirem impotentes frente à ordem do econômico, que se-lhes apresenta como natural e imutável, que os homens transferem seus mais preciosos desejos de realização para o âmbito da política. Como bem o expressa Chasin:

"O politicismo é intrínseco à ordem do capital: a ordem econômica é natural, a ordem política é o que resta para o homem configurar, e esta é decisiva, molda a convivência e realiza a justiça. A economia é [vista como] uma espécie de pano de fundo por si a-

\footnotetext{
${ }^{7}$ J. Habermas, Connaissance et Interêt. Paris: Gallimard, 1976, p. 92.

${ }^{8}$ J. Habermas, Théorie et Pratique. Paris: Payot, 1975, p. 38. 
morfo, ou melhor, uma plataforma virtual com várias possibilidades, que será decidida pela política 9 .

Assim é que, em Habermas, ação social é "uma forma de vida que se constitui na abstração" e a relação de forças sociais "aparece mais freqüentemente sob uma forma política" ${ }^{10}$. Sua teoria crítica, relegando a totalidade econômica às teorias econômicas, retira destas apenas aquilo que se ajusta às suas concepções. E, por isso, trata de uma realidade cindida em, de um lado, uma esfera econômica e, de outro, a esfera da sociabilidade.

Para Chasin, Habermas foi um dos que contribuíram ao fortalecimento do marxismo vulgar:

"Operações redutoras que perfilaram uma versão do marxismo circunscrito à condição de lógica ou método analítico e de ciência do capitalismo, para a qual ficou irremediavelmente perdido o centro nervoso do pensamento marxiano - a problemática, real e idealmente inalienável, da emancipação humana ou do trabalho, na qual e somente pela qual a própria questão da prática radical ou críticorevolucionária encontra seu télos, identificando na universalidade da trama das atividades sociais seu território próprio e resolutivo, em distinção à finitude da política, meio circunscrito dos atos negativos nos processos reais de transformação ${ }^{11}$.

Ao se relegar o primado ontológico do ser social incorre-se numa visão epistemologizante da sociabilidade. A sociabilidade é, em Habermas, uma forma de vida que se constitui na abstração e, portanto, a apologia da política - abstração mais perfeita da vida real - não é algo fortuito. De acordo com Marx,

"O Estado abole, a seu modo, a diferença de nascimento, de condição, de instrução, de emprego, quando ele declara que nascimento, condição, instrução, emprego são diferenças não políticas; quando, sem tomar em conta estas diferenças, ele proclama que cada membro do povo participa à soberania do povo de forma equivalente" ${ }^{, 12}$.

\footnotetext{
9 J. Chasin, "Rota e prospectiva de um projeto marxista". In: Ad Hominem. São Paulo, no 1,1999 , p. 38 .

${ }^{10}$ Habermas, Connaissance et Interêt op.cit., p. 84.

${ }^{11}$ Chasin, "Rota e prospectiva de um projeto marxista", op.cit., p.11.

${ }^{12}$ Karl Marx, La Question Juive. Paris: Aubier Montaigne, 1971, p. 70.
} 
O Estado ou a forma de organização política moderna é exatamente a abstração das diferenças reais - a dissolução de suas características no plano da abstração. Relega-se, nesta vertente marxista, com a qual Habermas apenas contribui, não um suposto paradigma do trabalho - visto que, segundo Chasin, em Marx tal "paradigma" não existe - mas, sim, os lineamentos de uma ontologia do ser social, "do ser auto-constituinte, na qual o trabalho é uma categoria central ou fundante, uma vez que a individualidade humano-societária é 'atividade sensível', aí compreendidos seus característicos e inseparáveis 'momentos ideais' (... $)^{13}$. Em outras palavras, relega-se o legado mais precioso da obra de Marx na qual, segundo Lukács, "pela primeira vez na história da filosofia, as categorias econômicas aparecem como as categorias da produção e reprodução da vida humana" ${ }^{14}$ (grifo meu).

As categorias econômicas marxianas expressam não uma dada ordem de efetividades cindidas que caracterizariam o ser social e em cujo seio a economia seria fator preponderante. Ao contrário, a abstração e unilateralização dos conceitos é exatamente o que Marx combateu em sua crítica à economia política. Nos Manuscritos de 1844, mostra que os economistas que, como Smith, reconheceram o trabalho como essência da propriedade privada - superando a visão de exterioridade desta última - deixaram, porém, de ver a outra metade da realidade: a essência do homem transmutada em propriedade privada, ou seja, o fato da alienação. E isto porque

"A economia política parte do fato da propriedade privada. Ela não o explica-nos. Ela exprime o processo material que descreve, em realidade, a propriedade privada em fórmulas gerais e abstratas que, em seguida, têm para ela valor de leis. Ela não compreende estas leis, isto é, ela não mostra como elas resultam da essência da propriedade privada" ${ }^{, 15}$.

\footnotetext{
${ }^{13}$ Chasin, "Rota e prospectiva de um projeto marxista", op.cit. , p. 12

${ }^{14}$ Apud Chasin, J., Marx - Estatuto Ontológico e Resolução Metodológica. São Paulo: Ensaio, 1995, p. 378.

${ }^{15}$ Karl Marx, Manuscritos Econômicos Filosóficos - primeiro manuscrito. São Paulo: Nova Cultural, 1991, p. 54.
}

60 A TEORIA CRÍTICA DE HABERMAS FRENTE À PERSPECTIVA ONTO-PRÁTICA DE MARX 
Ao contrário de Habermas, Marx, ao tomar como base não uma realidade cindida, abstraída, mas a totalidade das determinações do concreto, buscou a todo momento a dilucidação de nexos reais, não se contentando com afirmações nem mesmo do que reconhecia como sendo a melhor expressão da cientificidade de sua época.

Em A Miséria da Filosofia, Marx diz ainda:

"As categorias econômicas são expressões teóricas das relações sociais de produção ... Os mesmos homens que estabelecem as relações sociais de acordo com a sua produtividade material, produzem também os princípios, as idéias, as categorias, de acordo com suas relações sociais" $"$.

Para Marx, a práxis social é exatamente a práxis do trabalho, atividade sensível, essência humana inseparável de seu momento ideal, ou seja, da produção de idéias.

Habermas e Marx situam-se, portanto, em posições diametralmente opostas na medida em que aquele realiza exatamente o que Marx combateu: unilateralização das categorias tomadas às análises econômicas e cisão entre o 'econômico' e o 'social'; determinação da política como esfera resolutiva e, portanto, como veio emancipatório.

${ }^{16}$ Apud Vaisman, E., "A Usina Onto-Societária do Pensamento". In: Ad Hominem. São Paulo, no 1, p. 261. 